Original Article

\title{
Surgical Outcome of Sellar Suprasellar Brain Tumors through Retracterless Subfrontal Approach
}

\author{
Rana Zubair Mahmood, Imran Bajwa, Sayed Ali Zunair, Touqeer Ahmad, Habib Sultan, \\ Shoqaib Mehmood \\ Neurosurgery Unit, Punjab Institute of Neurosciences (PINS), Lahore Pakistan
}

\section{ABSTRACT}

Objectives: The aim of this study is to see the surgical outcome of Sellar and Suprasellar brain tumors with retractorless modified subfrontal approach.

Material and Methods: We did cohort study of 15 patients who were operated in Neurosurgery Unit 2, PINS. Our study duration is 1 year and follow up duration is of 3 months. Clinical features were related to cranial nerves $2^{\text {nd }}, 3^{\text {rd }}, 4^{\text {th }}$, and pituitary gland, dural irritation and temporal lobe compression i.e., diplopia, decrease vision, CSF rhinorrhea, abnormal olfaction, headache, GTCS etc.

Results: In our study, age range was $8-62$ years with mean age was 35 years. Our 5 patients were male and 10 patients were female. Surgery was performed in all patients through subfrontal approach with retractorless method. In Histopathological report of 2 patients' findings was Craniopharyngioma, 12 were of pituitary adenoma and 1 was of sellar meningioma. Seven 46.67 percent patients operated successfully with no new neurological deficit. Three 20 percent patients operated but no post op improvement in clinical symptoms, no patients were re-explored postoperatively due to CSF Rhinorrhea. Diabetes Insipidus occurred in 5 (33.3\%) patients post-operatively which was managed later on.

Conclusion: Surgery subfrontal approach with retractorless method is the safe corridor for treatment of sellar and Suprasellar brain tumors.

Keywords: Sellar and Suprasellar brain tumors, Retractorless Method, Subfrontal Approach.

Corresponding Author: Rana Zubair Mahmood

Punjab Institute of Neurosciences (PINS)

Lahore Pakistan

Email: ranazubair356@gmail.com

Date of Submission: 20-01-2021

Date of Revision: 15-03-2021

Date of Online Publishing: 31-03-2021

Date of Print: 31-03-2021

DOI. 10.36552/pjns.v25i1.530

\section{INTRODUCTION}

Our all patients presented with a history of decreased vision, one patient presented with a complaint of anosmia, four patients presented with a history of fits, all patients gave a history of headache, one patient presented with features of acromegaly. The hypothalamus regulates the function of the pituitary gland which is located just above sella turcica. The internal carotid arteries; cranial nerves III, IV, and $\mathrm{VI}$; and the 
ophthalmic and maxillary divisions of cranial nerve $\mathrm{V}$ lies within the cavernous sinus. The pituitary stalk passes through the diaphragma sella and contains the pituitary portal veins and neuronal processes. The anterior pituitary secretes six different hormones i.e., adrenocorticotropic hormone $(\mathrm{ACTH})$, thyroid-stimulating hormone $(\mathrm{TSH})$, prolactin $(\mathrm{PRL})$, growth hormone $(\mathrm{GH})$, and follicle-stimulating hormone (FSH) and luteinizing hormone (LH). The posterior pituitary secretes antidiuretic hormone (ADH) and oxytocin. ${ }^{1,2,3,5,6,7,8,9,10,11,12}$

The annual incidence of pituitary adenoma is 25 per 1 million people and they constitute $10 \%$ to $15 \%$ of primary intracranial tumors. Pituitary tumors with a diameter of less than $10 \mathrm{~mm}$ are called microadenomas, greater than $10 \mathrm{~mm}$ are called macroadenomas and those tumors greater than4 $\mathrm{cm}$ are called giant adenomas. Microadenomas occur in women of middle age. Macroadenomas occur in men in old age. Approximately $30 \%$ of pituitary tumors are classified as nonfunctioning adenomas and they manifest with symptoms of pressure effect. ${ }^{4}$

We can see enlarged, round sella and doubled sellar floor on plain radiographs. Magnetic resonance imaging (MRI) will show the size and location of the lesion as well as its relationship with surrounding structures. To see the sphenoid sinus anatomy, we do a computed tomography (CT) scan.

Endoscopic transsphenoidal resection of the tumor is considered the first-line treatment option for non-functioning adenomas. With significant supratentorial tumor extension, a transcranial approach is used..$^{13,14,15,16,17,18,19} \mathrm{~A}$ postoperative imaging should be done at least 4 to 6 weeks after surgery.

\section{MATERIAL AND METHODS}

\section{Study Design}

A prospective observational study was conducted on 15 patients who were operated in Punjab
Institute of Neurosciences (PINS) in Neurosurgery Unit 2 for one year from $1^{\text {st }}$ January 2020 to $31^{\text {st }}$ December 2020. A prior ethical approval was taken for the study from the institutional review board. All patients' consents were also taken as per protocol.

\section{Inclusion Criteria}

Those patients ( $8-62$ years) included who were having sellar and suprasellar brain tumors.

\section{Exclusion Criteria}

Previous operated case of pituitary tumors were excluded.

\section{Operative Technique}

In retractorless subfrontal approach, we performed routine frontal craniotomy. Dura was opened. Then we sucked CSF for few minutes till the brain gets relaxed. Then we gradually proceeded to the pituitary tumor by making space by putting cotton patties towards the brain surface. Continuous suction of the CSF was performed with the sucker and bipolar diathermy forceps till the tumor was reached. After this, instead of applying the brain reactor, we used cotton pattiews and bipolar diathermy forceps to repose the tumor. The more capsule uses us given continuous suction of the tumor by the sucker. The remaining procedure for tumor removal was same.

Total resection of the tumor was performed in all patients through a sub frontal approach with retractorless technique. MRI and CT scans were conducted post-surgically in all patients. The post-op CT the scan was performed after 12 hours to observe any residual tumor and bleed, brain edema due to surgery.

\section{Data Collection}

Patient's data was entered on preformed 
proforma for collection. SPSS version 22 was used for data analysis.

\section{Data Analysis}

All patients had sellar and suprasellar tumors on imaging i.e. MRI were included in our study. Postoperative CT scan and MRI were tools to see complications and residual tumors.

\section{RESULTS}

\section{Age Incidence}

Age range was $8-62$ years and mean was 35 years.

\section{Gender Incidence}

Five patients $(30 \%)$ were male and ten patients (70\%) were female.

\section{Clinical Presentation}

Clinical presentation shown in Table 1.

\section{Histopathology}

In histopathological reports findings, 2 (13.33\%) patients were with craniopharyngioma, 12 (80\%) were found adenoma and 1 (6.67\%) patient was diagnosed with sellar meningioma.

\section{Outcome}

The aim of this study is to see the surgical outcome of Sellar and Suprasellar brain tumors with retractorless subfrontal approach (Table 2). Seven (46.67\%) patients operated successfully with no new neurological deficit. Three (20\%) patients operated but no post op improvement in clinical symptoms, no patients were re-explored postoperatively due to CSF Rhinorrhea. Diabetes Insipidus occurred in $5(33.3 \%)$ patients postoperatively which was managed later on.

\section{Complications}

Temporary debates insipidus was done in 5 (33\%) patients. All patients recovered well in 3 months postoperatively.

Table 1: Clinical summary of 10 Patients of Sellar/Suprasellar Tumor.

\begin{tabular}{|c|c|c|c|c|}
\hline Cases & Age (Years) & Sex & Clinical Features & Duration \\
\hline \multirow{2}{*}{1} & \multirow{2}{*}{17} & \multirow{2}{*}{ Female } & a-Decreased vision in both eyes & $a-4$ years $b-3.5$ years \\
\hline & & & b-Fits c-Anosmia d-Headache & $c-2$ years $d-7$ years \\
\hline 2 & 10 & Male & $a-B l i n d n e s s \quad b$-Fits & $a-3$ years $b-4$ days \\
\hline 3 & 7 & Male & a-Left side decreased vision $b$-Headache & a- 1 month $b-2$ months \\
\hline 4 & 45 & Female & a-Left side decreased vision $b$-Headache & $a-3$ months b-months \\
\hline 5 & 50 & Female & $a-B l i n d n e s s \quad b-H e a d a c h e$ & $a-4$ months $b-6$ months \\
\hline 6 & 35 & Female & $a-B l i n d n e s s \quad b$-Headache & $a-10$ years $b-10$ years \\
\hline 7 & 62 & Male & a-Right side decreased vision b-Headache & $a-8$ years $b-9$ years \\
\hline 8 & 25 & Female & $a$-Decreased vision both eyes b-Headache & $a-1$ month $b-3$ months \\
\hline 9 & 33 & Female & $\begin{array}{l}\text { a-Right side decreased vision b-Headache } \\
\text { c-Acromegaly }\end{array}$ & $a-3$ years $b-5$ years $c-3$ years \\
\hline 10 & 45 & Female & a-Decreased vision both eyes b-Headache & $a-1$ month $b-1$ years \\
\hline 11 & 35 & Male & a-Left side decreased vision $b$-Headache & $a-1$ years $b-2$ years \\
\hline 12 & 41 & Female & a-Decreased vision both eyes b-Headache & $a-2$ months $b-1$ years \\
\hline 13 & 29 & Male & a-Right side decreased vision b-Headache c-GTCS & $a-3$ months $b-7$ months $c-1$ year \\
\hline 14 & 33 & Female & a-Decreased vision both eyes b-Headache & $a-1$ months $b-5$ years \\
\hline 15 & 44 & Female & a-GTCS b-Decreased vision both eyes c-Headache & $a-2$ years $b-5$ months $c-3$ years \\
\hline
\end{tabular}




\begin{tabular}{|lcc|}
\hline Table 2: Outcome of surgery. & \\
Outcome & No. of Patients & Percentage \\
Good & 7 & 46.67 \\
Complications & 5 & 33.3 \\
Mortality & 0 & 00 \\
No improvement & 3 & 20 \\
\hline
\end{tabular}

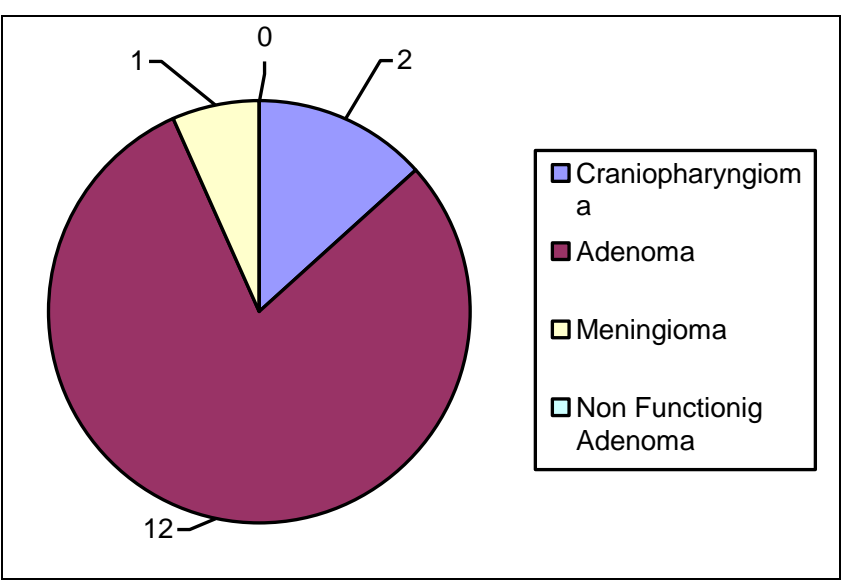

Figure 1: Biopsy Reports.

\section{DISCUSSION}

The mean age with pituitary adenoma is 35 years. In our study, the age range was from $8-62$ years. Most of our patients were between $30-5$ years of age. Pituitary adenoma accounts for $80 \%$ of intracranial tumors. Craniopharyngioma accounts for $13.3 \%$ of intracranial tumors. In our study, we had 5 male patients and 10 female patients. The male to female ratio was $1: 2$.

Our 15 patients presented with complaint of headache, 1 patient presented with complaint of acromegaly, 1 patient with anosmia, 15 with visual problems, our 4 patients presented with GTCS. All patients underwent total resection of the tumor; no subtotal resection was performed. Radiotherapy along with chemotherapy was provided to all patients postoperatively.

In biopsy study, 2 patients were diagnosed with craniopharyngioma, 12 with pituitary adenoma. 6 patients were diagnosed having prolactinoma, 6 with growth hormone-secreting adenoma, 2 patients with Craniopharyngioma, and 1 was diagnosed to have sellar meningioma. In all patients, the mode of diagnosis was pituitary hormones profile and radiology i.e., MRI. Post-operatively $\mathrm{CT}$ scan was performed in all patients to see complications and accuracy of surgery.

Immediately after the operation, the most common complication was diabetes insipidus. This occurred in 5 patients and it was transient, resolved with medical therapy. No patient had persistent diabetes insipidus. CSF leakage was not observed in any patients. No patients re-explored and treated.

Meningitis was another complication that did not occur in any case. We observed that meningitis mostly occurred in all those patients who had CSF leakage. In our study group, no such complication occurred. All these complications occur if the tumor size is large, the hypothalamic extension is present, older age, lack of experience of the neurosurgeon and if comorbidities present.

Post operatively DI occurred in five patients which were transient in nature. Medical therapy was given in the form of Desmopressin, and carbamazepine gave. Fluid replacement was given in the form of dextrose saline. Input and output monitored all patients recovered within 24 hours after the operation.

Our 3 patients did not show any improvement in vision as they were blind pre-operatively. In 7 patients, the vision was totally normal postoperatively. 1 Patient presented with clinical features of acromegaly. The outcome in this patient was not good.

\section{Advantages}

There is no incidence of brain contusion due to the softness of cotton patties which are used for the retraction of the brain as compared to the hard brain retractors. There is less chance of neurovascular damage due to retraction by soft patties. There is not much availability of literature 
on retractorless brain surgery so this being the first study.

\section{Limitations}

The number of cases was small. Hence large case series for further evaluation by this approach is awaited.

\section{CONCLUSION}

Surgery offered via modified sub frontal approach with retractorless method is a safe corridor as patients' outcome is very good. Post-operative complications are very rare by this method. Neurological status of all patients improved after surgery in the majority of cases.

\section{REFERENCES}

1. Pirahanchi $Y$, Jialal I. Stat Pearls [Internet]. Stat Pearls Publishing; Treasure Island (FL): Dec 17, 2018. Physiology, Thyroid.

2. Patel H, Tiwari V. Stat Pearls [Internet]. Stat Pearls Publishing; Treasure Island (FL): Oct 27, 2018. Physiology, Posterior Pituitary.

3. Shahid Z, Singh G. Stat Pearls [Internet]. Stat Pearls Publishing; Treasure Island (FL): Dec 9, 2018. Physiology, Hypothalamus.

4. Monson JP. The epidemiology of endocrine tumours. Endocrine-related cancer, 2000 Mar 1; 7 (1): 29-36.

5. Al-Shraim M, Asa SL. The 2004 World Health Organization classification of pituitary tumors: what is new? Acta Neuropathologica. 2006 Jan; 111 (1): 1-7.

6. Asa SL, Kovacs K. Clinically non-functioning human pituitary adenomas. Canadian Journal of Neurological Sciences, 1992; 19 (2): 228-35.

7. Snyder PJ. Clinically nonfunctioning pituitary adenomas. Endocrinology and metabolism clinics of North America. 1993; 22 (1): 163-75.

8. Greenman $Y$, Melmed S. Diagnosis and management of nonfunctioning pituitary tumors. Annu Rev Med. 1996; 47: 95-106.
9. Flickinger JC, Nelson PB, Maninez AJ, et al. Radiotherapy of nonfunctional adenomas of the pituitary gland. Results with long term follow-up. Cancer, 1989; 63: 2409-2414.

10. Greenman Y, Mclmed S. Diagnosis and management of nonfunctioning pituitary tumors. Annu Rev Med. 1996; 47: 95-106.

14. Elster AD. Imaging of the sella: anatomy and pathology. In Seminars in Ultrasound, CT and MRI, 1993 Jun 1; Vol. 14, No. 3: pp. 182-194. WB Saunders.

15. Chiang MF, Brock M, Patt S. Pituitary metastases. Neurochirurgia. 1990; 33 (04): 127-31.

16. Mortini P, Losa M, Barzaghi R, Boari N, Giovanelli $M$. Results of transsphenoidal surgery in a large series of patients with pituitary adenoma. Neurosurgery, 2005; 56 (6): 1222-33.

17. Alleyne $\mathrm{CHJ}$, Barrow DL, Oyesiku NM. Combined transsphenoidal and pterional craniotomy approach to giant pituitary tumors. Surg Neuro. 2002; 57: 380-390.

18. Ragel BT, Couldwell WT. Pituitary carcinoma: a review of the literature. Neurosurgical focus, 2004 Apr. 1; 16 (4): 1-9.

19. Knosp E, Steiner E, Kitz K, Matula C. Pituitary adenomas with invasion of the cavernous sinus space: a magnetic resonance imaging classification compared with surgical findings. Neurosurgery, 1993; 33 (4): 610-8.

20. Powell M. Recovery of vision following transsphenoidal surgery for pituitary adenomas. British Journal of Neurosurgery, 1995; 9 (3): 36774.

21. De Menis E, VISentin A, Billeci D, et al. Pituitary adenomas in childhood and adolescence. Clinical analysis of 10 cases. Endocrinol Invest. 2001; 24 (2): 92-97.

22. Artese $R, D^{\prime}$ Osvaldo $D H$, Molocznik I, Benencia $H_{\text {, }}$ Oviedo J, Burdman JA, Basso A. Pituitary tumors in adolescent patients. Neurological Research, 1998; 20 (5): 415-7.

23. Ikram MF, Sajjad Z, Shokh IS, Omair A. Pituitary gland volume on magnetic resonance imaging: Normative observations. Pak J Neurol Sci. 2007; 2: 141-4. 


\section{Additional Information}

Disclosures: Authors report no conflict of interest.

Ethical Review Board Approval: The study was conformed to the ethical review board requirements.

Human Subjects: Consent was obtained by all patients/participants in this study.

Conflicts of Interest:

In compliance with the ICMJE uniform disclosure form, all authors declare the following:

Financial Relationships: All authors have declared that they have no financial relationships at present or within the previous three years with any organizations that might have an interest in the submitted work.

Other Relationships: All authors have declared that there are no other relationships or activities that could appear to have influenced the submitted work.

\section{AUTHORS CONTRIBUTIONS}

\begin{tabular}{|l|l|l|}
\hline Sr.\# & Author's Full Name & Intellectual Contribution to Paper in Terms of: \\
\hline 1. & Rana Zubair Mahmood & Analysis of data, manuscript writing and methodology. \\
\hline 2. & Imran Bajwa & Study design\& data collection. \\
\hline 3. & Sayed Ali Zunair & Statistical analysis and manuscript writing. \\
\hline 4. & Touqeer Ahmad & Study design and data collection. \\
\hline 5. & Habib Sultan & Interpretation of results and Literature review. \\
\hline 6. & Shoqaib Mehmood & Literature review. \\
\hline
\end{tabular}

